\title{
Perspectives on Palliative Care Among Duchenne Muscular Dystrophy Patients and Their Families in Singapore
}

Sarah Jane Corpuz Tapawan, ${ }^{1}$ MD, MRCPCH (UK), Furene SJ Wang, ${ }^{2}$ MBBS, MMed (Paeds), MRCPCH (UK), Ming Wei Lee, ${ }^{1}$ MBBS, MMed (Paeds), MRCPCH (UK),

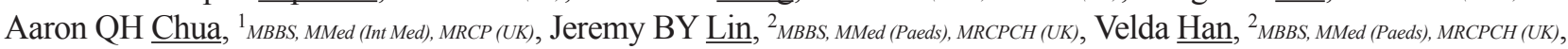
Michael TC $\underline{\text { Lim }},{ }^{2}$ MBBS, FRCPCH (UK), FCCP (USA), Hian Tat Ong, ${ }^{2}$ MBBS, MMed (Paeds), Stacey KH $\underline{\text { Tay }, ~}{ }^{1,2}$ MBBS, MMed (Paeds), FRCPCH (UK)

\begin{abstract}
Introduction: With better medical care, patients with Duchenne muscular dystrophy (DMD) now live longer but face more complex medical and social needs. This study described the perceptions of DMD patients and their families of disease-specific palliative care services in Singapore. Materials and Methods: A multicentre, crosssectional study involving DMD patients and their families was carried out. Structured questionnaires were administered to them to collect data on their understanding of palliative care, health services accessed and desired by them and quality of life. Results: A total of 30 pairs of DMD patients and their caregivers responded. Most patients were $>13$ years old $(70 \%)$ and non-ambulant $(86 \%)$. Most of them and their families $(\mathbf{7 0} \%)$ were also not aware of palliative care and support services that were available to them in Singapore. Additionally, they perceived greater financial assistance and better transport services as resources that could better meet their care needs. The presence of scoliosis and need for ventilatory support were associated with lower quality of life in patients. Conclusion: There is a need to improve awareness and provision of palliative care services for DMD patients in Singapore where discussion of end-of-life care is often considered taboo. Prevention and correction of scoliosis and provision of appropriate ventilatory support may improve quality of life in DMD patients.
\end{abstract}

Ann Acad Med Singapore 2020;49:72-7

Key words: Advance care planning, Palliative support services, Quality of life

\section{Introduction}

Duchenne muscular dystrophy (DMD) is an X-linked, progressive neuromuscular disorder that causes loss of mobility and comorbidities including cardiomyopathy, contractures, respiratory insufficiency, scoliosis and eventual loss of ability to care for oneself. ${ }^{1,2}$ Despite advances in medicine, DMD remains incurable. ${ }^{3}$ Without non-invasive ventilation (NIV), mean age of death in DMD patients in the past was 14.4 years $(95 \%$ confidence interval, 11.9-16.82 years). ${ }^{4}$ However, nocturnal ventilation has improved the likelihood of survival of up to 25 years in DMD patients. ${ }^{4}$

In the late stage of the disease, DMD patients are typically wheelchair-bound, on NIV support and dependent on others for their care. Their nutritional status is also greatly compromised from progressive swallowing dysfunction and they experience pain from scoliosis and contractures with poor sleep. ${ }^{5-7}$ Beyond the direct costs incurred by DMD patients for medical intervention, the impact of the disease on their caregivers and families can be huge since their extensive health needs can cause much emotional, financial and psychological stress on their resources and coping abilities. ${ }^{8,9}$ Increasingly, as DMD patients enjoy longer life expectancy, it means that the duration of nutritional, physical and social issues that significantly impact their quality of life has been extended.

Consequently, efforts to destigmatise and effect a change in the perceptions of the general population of palliative care as "giving up hope" still remains very much a work in progress. Poor awareness of "palliative care" in DMD patients and even health professionals

${ }^{1}$ Department of Paediatrics, Yong Loo Lin School of Medicine, National University of Singapore, Singapore

${ }^{2}$ Khoo Teck Puat-National University Children's Medical Institute, National University Health System, Singapore

Address for Correspondence: Dr Sarah Jane Corpuz Tapawan, Unit 9 45-49 Harbourne Road, Kingsford, NSW 2032, Australia.

Email: janesa0301@gmail.com 
has been reported..$^{10}$ The World Health Organization has defined palliative care for children as "the active total care of the child's body, mind and spirit, and also involves giving support to the family. It begins when illness is diagnosed, and continues regardless of whether or not a child receives treatment directed at the disease. Health providers must evaluate and alleviate a child's physical, psychological, and social distress. Effective palliative care requires a broad multidisciplinary approach that includes the family and makes use of available community resources; it can be successfully implemented even if resources are limited. It can be provided in tertiary care facilities, in community health centers and even in children's homes."11

The shift from an adult-centric approach to a childcentric one in palliative care will help to facilitate early integration of palliative care into the care plans for children and young patients of various diseases including: 1) conditions where cure is possible but may fail (such as cancer); 2) diseases that are progressive (such as neurodegenerative disorders); 3 ) incurable and progressive conditions but the child may live for an extended period of time (such as DMD); and 4) non-progressive conditions but with a shorter lifespan (such as cerebral palsy). ${ }^{12}$ This paradigm shift can be helpful and effective in addressing the unique needs that surface throughout the duration of life-limiting or lifethreatening conditions and to provide the best quality of life and care for every child. ${ }^{13}$ Early interventions had been shown to confer a positive effect on longevity and quality of life when patients and their families made changes to their care and life plans. ${ }^{14,15}$

To date, no studies in Singapore have sought to quantify the usage level and accessibility of palliative support services, identify barriers to their use and assess the degree of awareness and understanding of palliative care by DMD patients and their families. To address this gap in the literature, our study aimed to provide a situation analysis of the state and accessibility of palliative care. It also attempted to shed light on the understanding of palliative care among DMD patients and their families in Singapore.

\section{Materials and Methods}

This was a multicentre, cross-sectional study involving outpatient male DMD patients who were identified from the multidisciplinary neuromuscular clinics in the paediatrics department of the National University Hospital (NUH) and Muscular Dystrophy Association Singapore (MDAS). Informed consent was obtained from patients and their families. Ethics approval was granted by the Domain Specific Research Board of the National Healthcare Group, Singapore.

Patients were recruited over a 6-month period using purposive sampling. Data was collected through interviews with them and their caregivers using structured questionnaires that evaluated functional mobility, demographics, palliative services that they had accessed and desired and their understanding of palliative care. Monthly family household income was dichotomised to either above or below $\mathbf{\$} \$ 6000$ for the purpose of analysis, as it was the mean monthly household income in Singapore at the commencement of this study. ${ }^{16}$

Data on quality of life of patients and caregivers were collected using 2 validated questionnaires: the Pediatric Quality of Life Inventory ${ }^{\mathrm{TM}}$ (PedsQL ${ }^{\mathrm{TM}}$ ) Family Impact Module and the parental and ageappropriate child reports, PedsQL ${ }^{\text {TM }}$ Neuromuscular Module (Version 3.0). For the latter, patients completed either the Young Child report (for those aged 5-7 years old ), Child report (aged 8-12 years old) or Teen report (aged 13-18 years old).

No sample calculation was done. Statistical analyses were performed using SPSS Statistics for Windows, Version 20.0 (IBM Corp., Armonk, NY, USA). The relationship between service outcomes and predictive variables was derived from multivariate analysis.

\section{Results}

A total of 33 patients were screened. Most (77.0\%) of them were identified from NUH. One patient and his family declined to provide consent and another retracted their consent after they felt that the questions posed to them were too sensitive. Eventually, 30 pairs of DMD patients and their families completed the questionnaires. Table 1 shows their demographic and clinical profile. Median age of patients was 17 years (range, 7-29 years) and $21(73.0 \%)$ of them were $\geq 13$ years old and mostly wheelchair-bound. Eight (26.7\%) of them were on NIV. Non-ambulant patients who had intact hand functions were able to manoeuvre their motorised wheelchairs.

Table 2 shows the usage frequency of health services by the patients. About $80 \%$ of them were on followup by the cardiologist, respiratory physician and physiotherapist that were consistent with the late stage of the disease. MDAS was their primary source of social support and $24(80.0 \%)$ of them desired respite care. For services that were already available in Singapore, the desire for more accessible transport services topped the list for $27(90.0 \%)$ of them while $25(83.0 \%)$ of them indicated a desire for a case manager and home 
Table 1. Demographic and Clinical Profile of Duchenne Muscular Dystrophy Patients

\begin{tabular}{|c|c|}
\hline Variable & Patients $(n=30)$ \\
\hline Median age in years (range) & $17(7-29)$ \\
\hline At diagnosis & $6(0-11)$ \\
\hline At onset of symptoms & $5(2-11)$ \\
\hline Age when wheelchair was needed & $10(6-15)$ \\
\hline Monthly household income $\leq$ S\$6000 (\%) & $18(60.0)$ \\
\hline Chinese ethnicity (\%) & $26(86.7)$ \\
\hline $\begin{array}{l}\text { Patients who required non-invasive } \\
\text { ventilation }(\%)\end{array}$ & $8(26.7)$ \\
\hline Patients with scoliosis (\%) & $17(56.7)$ \\
\hline Patients with contractures $(\%)$ & $20(66.7)$ \\
\hline \multicolumn{2}{|l|}{ Mobility (\%) } \\
\hline Ambulate independently & $4(13.3)$ \\
\hline Uses manual wheelchair & $7(23.3)$ \\
\hline Uses motorised wheelchair & $19(63.3)$ \\
\hline \multicolumn{2}{|l|}{ Scope of care needed $(\%)$} \\
\hline Shower & $24(80.0)$ \\
\hline Dressing & $23(76.7)$ \\
\hline Bringing patient outdoors & $21(70.0)$ \\
\hline Transfers & $20(66.7)$ \\
\hline Feeding & $15(50.0)$ \\
\hline Turning during sleep & $15(50.0)$ \\
\hline
\end{tabular}

respiratory care services. Finally, $14(50.0 \%)$ of them wanted pain management service.

Patients resided in public flats with a mean family size of 5 members (range, 3-8 individuals). Among them, 18 $(60.0 \%)$ had monthly household income $\leq \mathrm{S} \$ 6000$. After medical subsidies given by the Singapore government, $14(46.7 \%)$ patients and their families still required financial assistance. Consequently, greater financial support was listed as a desired service by them (76.7\%).

However, only $9(30.0 \%)$ patients and their families were aware of palliative care and $22(73.0 \%)$ of them had never heard of Advance Medical Directive (AMD). After they viewed a simple description of AMD provided in the questionnaire, $19(63.3 \%)$ caregivers agreed to support patient's decision to either accept or refuse medical intervention upon turning 21 years old.

Table 3 shows significant differences in reports between patients and their parents pertaining to the dimension on "about my neuromuscular disease" in the neuromuscular module $(P=0.041)$. Parents believed
Table 2. Utilisation of Health Services in Singapore by Duchenne Muscular Dystrophy Patients

\begin{tabular}{|c|c|}
\hline Service & $\begin{array}{l}\text { Patients, } \\
\text { n }=\mathbf{3 0}(\%)\end{array}$ \\
\hline \multicolumn{2}{|l|}{ Current access to } \\
\hline Cardiologist & $26(86.7)$ \\
\hline Physiotherapy & $25(83.3)$ \\
\hline Respiratory physician & $24(80.0)$ \\
\hline Neurologist & $23(76.7)$ \\
\hline Social support group in MDAS & $23(76.7)$ \\
\hline Orthopaedic surgeon & $16(53.5)$ \\
\hline $\begin{array}{l}\text { Financial support (through medical social } \\
\text { worker) }\end{array}$ & $14(46.7)$ \\
\hline Transport service & $13(43.3)$ \\
\hline Occupational therapy & $12(40.0)$ \\
\hline Pastoral or religious support & $8(26.7)$ \\
\hline Respiratory therapy service & $6(20.0)$ \\
\hline Speech therapy & $5(16.7)$ \\
\hline Home nursing support & $4(13.3)$ \\
\hline \multicolumn{2}{|l|}{ Desired access to } \\
\hline Enhanced transport service & $27(90.0)$ \\
\hline Case manager* & $25(83.3)$ \\
\hline Home respiratory support* & $25(83.3)$ \\
\hline Respite care & $24(80.0)$ \\
\hline Greater financial support & $23(76.7)$ \\
\hline Pain management & $15(50.0)$ \\
\hline
\end{tabular}

MDAS: Muscular Dystrophy Association of Singapore *Not available in Singapore.

that the disease was causing more physical problems in patients than what was perceived by the latter. Our study did not explore the reasons for this difference.

Independent factors that affected health-related quality of life (HRQoL) were identified from multivariate analysis. Presence of scoliosis and lower family income were associated with low HRQoL (Table 4). Patients and their parents also attributed low HRQoL to the need for ventilatory support. However, only caregivers reported that the presence of scoliosis was linked to low HRQoL in patients.

\section{Discussion}

In our study, DMD patients ( $30 \%$ ) had poor knowledge of "palliative care". This finding could be attributed to the likelihood that palliative care is still perceived 
Table 3. Parental and Child Reports on Pediatric Quality of Life Inventory ${ }^{\mathrm{TM}}$ Neuromuscular Module

\begin{tabular}{lcccc}
\hline Dimension & Median Parental Report (Range) & Median Child Report (Range) & $P$ Value \\
\hline About my neuromuscular disease & $62.5(14.7-86.8)$ & $67.65(16.2-97.1)$ & 0.041 \\
Communication & $66.67(0-100)$ & $58.33(16.7-100)$ & $>0.05$ \\
About our family resources & $55(20.0-100)$ & $62.5(20.0-100)$ & $>0.05$ \\
Total score & $61(17.0-88.5)$ & $66.83(21.0-87.0)$ & \\
\hline
\end{tabular}

as terminal care in conditions such as cancer than in life-limiting disorders like DMD. Although AMD is available for close to 2 decades, its awareness and use remain low. ${ }^{17}$ In our study, less than one-third of patients and their families were aware of AMD. Eventually, over half of them reported that they would support the patient's choice after AMD was made known to them.

Our study did not examine knowledge of advance care planning (ACP) in DMD patients and their families. Nevertheless, the need for ACP to better prepare families and provide a continuum of care to support them as the disease progresses - and at the same time provide optimal control of physical symptoms in patientsshould be emphasised. ${ }^{14}$ Previous studies had identified barriers that precluded consideration of ACP and AMD including lack of knowledge of palliative care, lack of acess to supportive services and cultural aversion to the taboo subject of end-of-life care (especially in an Asian country like Singapore). ${ }^{18,19}$ However, it is anticipated that as more DMD patients live longer into adulthood, the need to educate them and their families on ACP and AMD will become greater.

Our study found that $50 \%$ of patients and their families who were aware of palliative care felt that existing support services were inadequate, suggesting that such

Table 4. Factors Affecting Health-related Quality of Life

\begin{tabular}{lc}
\hline Variable & $\boldsymbol{\beta}(\mathbf{9 5 \%} \mathbf{C I})$ \\
\hline PedsQL & \\
\hline Presence of scoliosis & $-21.9(-36.4--7.4)$ \\
\hline Monthly household income $\leq \mathrm{S} \$ 6000$ & $-16.7(-27.7--5.8)$ \\
\hline PedsQL ${ }^{\mathrm{TM}}$ Neuromuscular Module & \\
\hline Requires ventilatory support & $-12.6(-24.0--1.2)$ \\
\hline Parent proxy & $-18.7(-31.5--5.8)$ \\
\hline Child & $-13.2(-23.2--3.2)$ \\
\hline Presence of scoliosis
\end{tabular}

$\beta$ : Beta coefficient; CI: Confidence interval; PedsQL ${ }^{\mathrm{TM}}$ : Pediatric Quality of Life InventoryTM services remain suboptimal in the country. Since DMD patients make repeat visits to various health providers as the disease progresses, there is a need to increase accessibility to various palliative support services that are offered in the community.

Most families (83.3\%) also indicated a desire for a case manager who can render personalised and consistent continuity of care to patients with complex medical conditions. In Singapore, this role is currently undertaken by the physician who attends to the patient on a regular basis. In the long run, it is not a feasible arrangement in view of the high patient load that every physician sees in public hospitals throughout the country. Currently, primary care practitioners also play a limited role in end-of-life care. ${ }^{20}$ To address this situation and improve the delivery of palliative care services to DMD patients, case managers and nurses can be trained to provide specialised and holistic care to this group of patients. ${ }^{21}$

In our patients, utilisation of medical care was high and this could be attributed to selection bias of patients who attended the multidisciplinary neuromuscular clinics. Most (73\%) of them were older non-ambulant boys ( $\geq 13$ years old). Loss of independent ambulation was associated with nocturnal hypoventilation and eventual NIV support, even in asymptomatic children with neuromuscular disorders. ${ }^{22,23}$ About $25 \%$ of our patients were on NIV support, yet only $6(20 \%)$ of them were recipients of respiratory therapy. Not surprisingly, $25(83.3 \%)$ patients desired to be offered home respiratory care services.

Pain has been reported by non-ambulant DMD patients. ${ }^{24}$ Although most of our non-ambulant patients had intact hand functions that allowed them to manoeuvre their motorised wheelchairs, they still required assistance in turning to relieve them of the pain from remaining in the same position over long periods of time. Consequently, our finding that nearly $50 \%$ of them desired pain management service is hardly surprising.

Half of our DMD patients required assistance in activities of daily living such as feeding, shower and transfers, and 16 caregivers had helpers to mitigate 
caregiver exhaustion. Nevertheless, most $(80 \%)$ of them required respite care. Although respite care can alleviate the caregiving burden of individuals caring for patients with chronic needs, it is not part of the standard of care. ${ }^{25,26}$ In MDAS, caregivers are offered short-term breaks in a designated room while others tend to their sons who are participating in its programmes. Star PALS, a paediatric palliative care service in Singapore, also offers home and respite care. The provision of accessible and flexible family-centered, home-based respite care to support families in caring for children with complex needs should form part of the standard of care.

Although Singapore is a small city-state and medical care is within easy reach of her residents, this study found that the safe transport of non-ambulant DMD patients was a valid concern. Although the country has invested heavily to upgrade and develop its public transport infrastructure to accommodate individuals with disabilities, non-ambulant DMD patients still struggle to use public transport since their motorised wheelchairs are often too bulky and heavy and they do not fit into a regular taxi or sedan. For reasons of safety and comfort, it is important for them to use a vehicle that is fitted out with a wheelchair retention system. In our patients, $27(90.0 \%)$ of them were vocal in their wish to have more transport options made available to them. Consequently, our institution has partnered various charities to fund regular transport services to fetch patients for their hospital appointments and return them home when completed. However, a more innovative and sustainable funding model is needed to meet the need of this group of patients.

Another key finding of our study was the economic cost and burden of disease DMD has on families and society which are magnified as the disease progresses. ${ }^{8}$ In our study, about $60.0 \%$ of patients and families had monthly household income $\leq \mathrm{S} \$ 6000$ (or $\mathrm{S} \$ 72,000$ per annum) that was comparable to the mean household income in Singapore. With a complex disease like DMD, its impact on the finances of patients and their families is substantial. Consequently, 23 patients and their families indicated that they would like to be awarded more financial assistance. With longer life expectancy, there is greater need for financial support by DMD patients to meet their increasing medical costs from hospitalisation, medications, clinic visits and purchase of assistive devices. Additionally, the economic burden on the household and society-in terms of lost productivity - will be felt when their caregivers are forced to cut back on their work hours or to cease employment altogether to care for them. Clearly, there is a need to formulate robust policies and programmes that can help to ease the financial hardship faced by DMD patients and their families.

Parents of the patients reported that the presence of scoliosis was associated with low quality of life in their children. With loss of ambulation, neuromuscular scoliosis from pelvic imbalance sets in. ${ }^{6}$ The discomfort a patient experiences from sitting over a long period of time-which worsens as the patient deteriorates gradually-necessitates the use of fitting orthotic devices and appropriate wheelchairs and early evaluation for surgical stabilisation of the spine. Although the presence of pain was not specifically asked in our study, it may be an important parameter that affected quality of life in our patients. Consequently, pain assessment should be included as part of screening and care assessment.

Both parents and patients reported that the need for ventilatory support was associated with low quality of life. Some studies had reported that the need for NIV did not correlate with poorer quality of life, and that home ventilation could lead to improvement in quality of life. ${ }^{27,28}$ However, in their study of 80 ventilator-assisted DMD patients, Bach et al found that $12.5 \%$ of them reported dissatisfaction with their life. ${ }^{29}$ Moreover, Baiardini et al reported that the use of wheelchairs and ventilators were significantly associated with lower quality of life..$^{30}$

\section{Conclusion}

As the epidemiologic profile of DMD patients changes, palliative care is important to address the complexity of their evolving needs and to ensure good quality of life for them and their families. More effort is needed to improve awareness of palliative care and for it to begin early in DMD patients. There is a need to develop robust and sustainable palliative care services including ACP and respite care, and more specialised, wheelchair-friendly public transport facilities are needed too. As DMD patients live longer, greater financial support is helpful to cushion the financial burden of the disease on patients and their families. Medical interventions such as prevention or early treatment of scoliosis and proper ventilatory support can help improve the quality of life of DMD patients. Although DMD remains incurable, there is much that can be done to help patients and their families enjoy a reasonable quality of life.

\section{Acknowledgements}

The authors would like to thank the patients and their families for their participation in the study. They also express their gratitude to the Muscular Dystrophy Association of Singapore for their immense support of this study. 


\section{REFERENCES}

1. Arias R, Andrews J, Pandya S, Pettit K, Trout C, Apkon S, et al. Palliative care services in families of males with Duchenne muscular dystrophy. Muscle Nerve 2011;44:93-101.

2. Bushby K, Finkel R, Birnkrant DJ, Case LE, Clemens PR, Cripe L, et al. Diagnosis and management of Duchenne muscular dystrophy, part 1: diagnosis, and pharmacological and psychosocial management. Lancet Neurol 2010;9:77-93.

3. Tay SKH, Lin JBY. Current strategies in management of Duchenne muscular dystrophy: allowing patients to live with hope. Ann Acad Med Singapore 2012;41:44-6.

4. Eagle M, Baudouin SV, Chandler C, Giddings DR, Bullock R, Bushby K. Survival in Duchenne muscular dystrophy: improvements in life expectancy since 1967 and the impact of home nocturnal ventilation. Neuromuscul Disord 2002;12:926-9.

5. Rahbek J, Werge B, Madsen A, Marquardt J, Steffensen BF, Jeppesen J. Adult life with Duchenne muscular dystrophy: observations among an emerging and unforeseen patient population. Pediatr Rehabil 2005;8:17-28.

6. Fujak A, Haaker G, Funk J. Current care strategies for Duchenne muscular dystrophy. Orthopade 2014;43:636-42.

7. Bloetzer C, Jeannet PY, Lynch B, Newman CJ. Sleep disorders in boys with Duchenne muscular dystrophy. Acta Paediatr 2012;101:1265-9.

8. Landfeldt E, Lindgren P, Bell CF, Schmitt C, Guglieri M, Straub V, et al. The burden of Duchenne muscular dystrophy: an international, cross-sectional study. Neurology 2014;83:529-36.

9. Chaturvedi SK. Exploration of concerns and role of psychosocial intervention in palliative care- a study from India. Ann Acad Med Singapore 1994;23:256-60.

10. Strand JJ, Kamdar MM, Carey EC. Top 10 things palliative care clinicians wished everyone knew about palliative care. Mayo Clin Proc 2013;88:859-65.

11. World Health Organization. Definition of palliative care. Available at: https://www.who.int/cancer/palliative/definition/en/. Accessed on 5 March 2020

12. International Children's Palliative Care Network. What is children's palliative care? Available at: http://www.icpen.org/about-icpen/whatis-childrens-palliative-care/. Accessed on 5 March 2020.

13. Together for Short Lives. Introduction to children's palliative care. Available at: https://www.togetherforshortlives.org.uk/changing-lives/ supporting-care-professionals/introduction-childrens-palliative-care/. Accessed on 5 March 2020.

14. Kang TI, Munson D, Hwang J, Feudtner C. Integration of palliative care into the care of children with serious illness. Pediatr Rev 2014;35:318-25.

15. Levine DR, Baker JN. Early palliative care for children with cancer: a multi-institutional survey study of pediatric oncology patients and parents. J Clin Oncol 2016;4:10582.
16. Ministry of Manpower, Singapore. Summary Table: Income. Available at: http://stats.mom.gov.sg/Pages/Income-Summary-Table.aspx. Accessed on 6 May 2018.

17. Pérez M del V, Macchi MJ, Agranatti AF. Advance directives in the context of end-of-life palliative care. Curr Opin Support Palliat Care 2013;7:406-10

18. Ng R, Chan S, Ng TW, Chiam AL, Lim S. An exploratory study of the knowledge, attitudes and perceptions of advance care planning in family caregivers of patients with advanced illness in Singapore. BMJ Support Palliat Care 2013;3:343-8.

19. Lesperance M, Shannon R, Pumphrey PK, Dunbar E, Genther $\mathrm{R}$, Coleman CL, et al. Training mid-level providers on palliative care: bringing advanced directives and symptom assessment and management to community oncology practices. Am J Hosp Palliat Care 2014;31:237-43.

20. Murray SA, Kok JY. Internationally, it is time to bridge the gap between primary and secondary healthcare services for the dying. Ann Acad Med Singapore 2008;37:142-4.

21. Finkelstein E, Malhotra C, Yee ACP. Improving the end-of-life experience in Singapore: building capacity in palliative care education and research. Ann Acad Med Singapore 2014;43:1-2.

22. Panitch HB. The pathophysiology of respiratory impairment in pediatric neuromuscular diseases. Pediatrics 2009;123:S215-8.

23. Katz SL, Gaboury I, Keilty K, Banwell B, Vajsar J, Anderson $\mathrm{P}$, et al. Nocturnal hypoventilation: predictors and outcomes in childhood progressive neuromuscular disease. Arch Dis Child 2010;95:998-1003

24. Zebracki K, Drotar D. Pain and activity limitations in children with Duchenne or Becker muscular dystrophy. Dev Med Child Neurol 2008;50:546-52.

25. Folden SL, Coffman S. Respite care for families of children with disabilities. J Pediatr Health Care 1993;7:103-10.

26. Thurgate C. Respite for children with complex health needs: issues from the literature. Paediatr Nurs 2005;17:14-8.

27. Kohler M, Clarenbach CF, Böni L, Brack T, Russi EW, Bloch KE. Quality of life, physical disability, and respiratory impairment in Duchenne muscular dystrophy. Am J Respir Crit Care Med 2005; 172:1032-6

28. Simonds AK, Muntoni F, Heather S, Fielding S. Impact of nasal ventilation on survival in hypercapnic Duchenne muscular dystrophy. Thorax 1998;53:949-52.

29. Bach JR, Campagnolo DI, Hoeman S. Life satisfaction of individuals with Duchenne muscular dystrophy using long-term mechanical ventilatory support. Am J Phys Med Rehabil 1991;70:129-35.

30. Baiardini I, Minetti C, Bonifacino S, Porcu A, Klersy C, Petralia P, et al. Quality of life in Duchenne muscular dystrophy: the subjective impact on children and parents. J Child Neurol 2011;26:707-13. 